\title{
The Reality of Business Reengineering: PACIFIC BelL'S CENTREX PROVISIONING PROCESS
}

\author{
Donna B. Stoddard \\ Sirkka L. Jarvenpaa \\ Michael Littlejohn
}

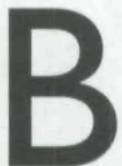

usiness process reengineering (BPR), a recently popularized phenomenon, is offered as a management change strategy when small incremental improvement in the way the business operates is too late or too little. ${ }^{1}$ Although some companies claim to have conducted BPR well before 1990, Michael Hammer helped to bring the BPR concept into broader corporate awareness in his 1990 Harvard Business Review article. ${ }^{2}$ Within the last 3 years, BPR appears to have permeated the vocabulary of most large management consulting organizations and has led organization after organization to create internal consulting groups with the challenge to reengineer their respective companies. The book by Hammer and Champy, Reengineering the Corporation, rose to the New York Times Best-Seller List one month after its publication date in $1993 .^{3}$

In late 1990, Pacific Bell, a subsidiary of Pacific Telesis Group and one of the seven Regional Bell Operating Companies, ${ }^{4}$ initiated reengineering. By the late 1980s the competitive environment for regional Bell operating companies was becoming increasingly complex. The growth in the use of cellular phones, of private branch exchanges, and cable networks all threatened the "plain old telephone service" that regional Bell operating companies traditionally controlled. In 1990, Pacific Bell's chief executive officer and president announced a longterm initiative called Competitive Readiness. The initiative called for 3 " $\mathrm{R}$ " $\mathrm{s}$ : restructuring, refocusing, and reengineering: 
- Restructuring led to breaking the once monolithic company into seven decentralized regional business units that served customers within specified geographic regions; statewide business units which focused on public and corporate customers with points of service throughout the state; and a product and technology support group composed of product and systems technology that permeated all facets of the firm's operations.

- The refocusing program led to organizing the firm's priorities and resources around vision, values, and bold goals. Bold goals were established for a number of key areas, including maintenance, provisioning or order fulfillment, revenue, job fulfillment, and customer complaints.

- Reengineering was seen as a more targeted and focused program than restructuring and refocusing. Reengineering was to apply many of the techniques of Total Quality Management, but result in quantum improvement.

A manager at Pacific Bell explained the relationship between traditional quality programs and reengineering: "Business process improvement is seen here as creating quantum improvement. It is an extreme case of improvement under the total quality umbrella." This view of the relationship between quality and reengineering echoes Davenport's assertions about the relationship between reengineering (or process innovation) and quality. ${ }^{5}$ Davenport goes as far as to say that "a company that is unsuccessful at one will probably not succeed at the other." ${ }^{\prime 6}$ This is in sharp contrast to Hammer and Champy who argue that quality and reengineering differ fundamentally given that quality programs seek steady, incremental improvement whereas reengineering seeks breakthrough improvements by discarding existing processes.

Centrex Provisioning was Pacific Bell's first reengineering project. Centrex, Pacific Bell's flagship offering to business customers, was a central officebased (as opposed to a customer premises-based) product offering to businesses. It provided advanced telephone features such as automatic callback, call forwarding, call holding, call waiting, and conference calling. The reengineering project was focused on the Centrex order fulfillment process, referred to as provisioning. Since each of Pacific Bell's seven regional business units had its own sales units and managed its respective central offices, Centrex service was provisioned within each of the seven regional business units. Customer marketing and operations data suggested that if Centrex was to remain competitive, the cost effectiveness and quality of the order fulfillment process would have to improve. Senior management believed that an incremental improvement would have been simply a band-aid approach. A totally new process was needed.

Pacific Bell's senior and middle management have formally recognized the project as successful. The Centrex reengineering project is also seen as successful by a number of outside groups, including AmeriTech, the San Francisco Chronicle, and Bellcore. A vice president at Pacific Bell summed up the fate of the project: “Centrex reengineering has been very successful where the project has 
been implemented." An executive vice president had this view: "The project was able to deliver its objectives. Centrex was an enormous success."

Each of the regions that implemented a variation of the new Centrex design realized cost reductions of $36-50 \%$, errors were reduced by $20 \%$ or more, service was delivered when the customer wanted it $99 \%$ of the time, and customer satisfaction ratings were $90 \%$ or higher. While these results were not earth shattering and were more modest than planned, regional management viewed the results as radical improvements.

The Centrex project also opened senior management's eyes to the potential of reengineering. In 1993, Pacific Bell launched a company-wide initiative called "Core Process Redesign" that was significantly influenced by the experience with the Centrex project. With Core Process Reengineering, management sought to "fundamentally rethink and redesign business processes to enable dramatic improvements in customer service, cost structure, and job design." The team identified 80 change initiatives encompassing every major corporate business process: order fulfillment, product development, marketing and selling, customer service, network creation and operations, procurement, facilities, systems, finance, human resources, regulatory, and governance. The magnitude of most of the identified change initiatives was similar to or greater than the change associated with Centrex Reengineering.

Nevertheless, Pacific Bell's reengineering experience and accomplishments suggest a somewhat different phenomenon than one might expect in light of the reengineering stories that have been published in the popular press. The understanding of the concepts and theory of BPR are still at their infancy. The concepts need to be developed and refined against the backdrop of projects that have attempted to put the embryonic concepts of reengineering to work.

We selected the Pacific Bell Centrex Reengineering project for in-depth study and analysis because it met the definition of BPR developed in an earlier phase of our research project (see Appendix). Thirty-five companies' reengineering efforts were surveyed to develop a definition of BPR (Figure 1). ${ }^{7}$ Those 35 reengineering efforts highlighted the wide variety of methodologies and approaches employed for reengineering. The commonality among the reengineering projects was the radical nature of the project performance objectives and the realization that those radical objectives would require organizational change that was much broader in scale and scope than had been attempted with previous organization change initiatives.

Not only did the Centrex project meet the empirically derived definition of reengineering, but Pacific Bell senior management approved and funded Centrex as a reengineering project. An external consulting firm was hired to train the project members on a reengineering methodology that guided the project activities. Members of the consulting firm also served as initial members of the reengineering team. ${ }^{8}$ 
FIGURE I. BPRDefinition

Reengineering is

- a cross-functional initiative

- business process focused

- simultaneous change to

- organization design,

- culture, and

- information technology

- to enable radical performance improvements

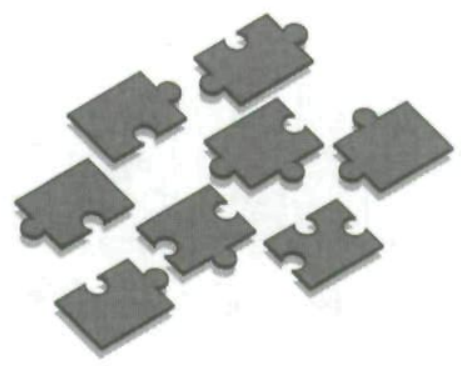

Our objective here is to refine managers' understanding of BPR concepts by comparing and contrasting Pacific Bell's reengineering experience, a project perceived to be successful, to the five assumptions of reengineering that are frequently touted by the "early writers" on reengineering. ${ }^{9}$ In the process, we will develop a set of reengineering assumptions that more closely reflect the implementation experiences of Pacific Bell (Table 3). Whereas BPR is different from the total quality approaches in design, during the implementation stage well done BPR is similar to total quality approaches. As the early writings of reengineering suggest, during design, BPR is radical, takes a clean slate approach, is process driven, top-down directed, and IT enabled. However, during the implementation stage, BPR is continuously incremental, constrained by the current organizational realities, subprocess focused, broadly participative, and initially relies on work role, work flow, and culture changes rather than advanced information technology. The notion that BPR is not significantly different in character from quality in implementation is at variance with Hammer and Champy. ${ }^{10}$

The first assumption of reengineering is that it involves radical change. Two characteristics of radical change are outcomes and time frame. Outcomes refer to the magnitude of the improvement and time frame refers to how long it should take to accomplish the change. A change that results in incremental improvement (e.g., a 10\% cost reduction) would not be considered a radical change and therefore would not be considered to be a satisfactory outcome from reengineering. Hammer and Champy argue, “Reengineering isn't about making marginal or incremental improvements but about achieving quantum leaps in performance." Similarly, Davenport maintains, "Process innovation [i.e., reengineering] is intended to achieve radical business improvement." Radical change involves dramatic and simultaneous change in business processes, jobs and structures, values and beliefs, and management and measurement systems. ${ }^{11}$

The second characteristic of radical change is that it occurs quickly. Hammer and Champy stated, "Reengineering can't be carried out in small and cautious steps. It is an all-or-nothing proposition that produces dramatically 
TABLE 3. Reengineering Results in Radical Change

\begin{tabular}{ll}
\hline $\begin{array}{l}\text { Reengineering Assumptions: } \\
\text { Early Writers }\end{array}$ & $\begin{array}{l}\text { Reengineering Assumptions: } \\
\text { Pacific Bell's Experience }\end{array}$ \\
\hline Reengineering results in radical change. & $\begin{array}{l}\text { Reengineering design may be radical, but implementation is } \\
\text { incremental. }\end{array}$ \\
\hline Reengineering assumes clean slate change. & $\begin{array}{l}\text { Reengineering design assumes clean slate change. However, } \\
\text { implementation will be limited by those constraints that management } \\
\text { cannot or will not remove. }\end{array}$ \\
\hline $\begin{array}{l}\text { Reengineering focuses on end-to-end } \\
\text { processes. }\end{array}$ & $\begin{array}{l}\text { Reengineering design focuses on end-to-end process redesign. } \\
\text { Reengineering implementation often focuses on the perceived most } \\
\text { broken pieces. }\end{array}$ \\
\hline Reengineering is top-down directed, & $\begin{array}{l}\text { Reengineering design is top-down directed but implementation must } \\
\text { be owned from the bottom-up. }\end{array}$ \\
\hline $\begin{array}{l}\text { Reengineering is information technology } \\
\text { enabled. }\end{array}$ & $\begin{array}{l}\text { Reengineering design is information technology enabled but } \\
\text { implementation might initiate without much of the assumed IT } \\
\text { capability. }\end{array}$ \\
\hline
\end{tabular}

impressive results." ${ }^{12}$ They advise that "twelve months should be long enough for a company to move from articulation of a case for action to the first field release of a reengineered process. ${ }^{\prime 13}$ Other writers of radical organizational change also describe such changes taking a short period of time, 6 to 24 months. ${ }^{14}$

The new design of the Centrex order fulfillment process indeed strove for radical changes in the process. The redesign assumed the availability of new roles, structures, and information technology-based systems that would result in quantum-leap improvements in cost, quality, time, and customer satisfaction (Table 4). The accomplishments of the implemented processes were quite a bit more modest.

At Pacific Bell, "stretch objectives" were very aggressive or bold goals. Their stretch objectives required a new process that was a major leap forward from the current state. The future state would include the capability to provide service when the customer wanted it, including same-day service. The service would also be error free. Traditionally, a Centrex customer's request for service was fulfilled in 5 to 15 days. The old process was costly and prone to errors because of the number of departments that had to be involved and the paper handoffs that occurred. An order often touched 11 systems and involved 8 to 10 people who were

\section{TABLE 4}

\begin{tabular}{ll}
\hline $\begin{array}{l}\text { Performance } \\
\text { Measure }\end{array}$ & Objective \\
\hline Cycle time & $\begin{array}{l}\text { Provide Centrex } \\
\text { service when the } \\
\text { customer wants it }\end{array}$ \\
\hline Cost & $\begin{array}{l}\text { Reduce internal } \\
\text { costs by } 75 \text { to } 80 \\
\text { percent }\end{array}$ \\
\hline Quality & Error-free orders \\
\hline Customer & 100 percent \\
Satisfaction & customer \\
\hline
\end{tabular}


from several functional areas and thus did not function as a team. Multiple handoffs were required, and an error at any point in the process could necessitate significant rework.

The redesign of the order fulfillment process, completed in 60 days, challenged the traditional work approaches that had emphasized functional specialization. The redesign assumed a case manager ${ }^{15}$ who would fulfill an order $80 \%$ of the time. That person would interface directly with the customer or account executive, enter the order, and provide a single point of contact up to the activation of service. The order would be fulfilled from an inventory of predefined packages that were already programmed in network software. In light of the number of individuals and departments that were involved in each order prior to the Centrex project, the notion that one person could provision a Centrex order from end to end was revolutionary. When a predefined package did not exist to fulfill the customer request, a "Virtual Team Scenario" would go into effect. Under this scenario, a team of functional experts physically residing in different locations would assemble the order. The employees would work on the order concurrently, rather than serially as in the past. The team did not specifically address cultural aspects. Nevertheless, changes in roles and structures were expected to promote values and norms that were aligned with the stretch objectives.

The Centrex reengineering team designed the new process and roles, assuming - for each scenario-the availability of new advanced information systems. Under the case management scenario, expert systems capabilities would be required to assist the Centrex service representative in executing end-to-end service. To facilitate communication and information flow among virtual team members for the remaining $20 \%$ of orders, the team envisioned a new information system that would allow the members of a virtual team to simultaneously access and manipulate information.

A 60-day trial was planned for the first quarter of 1992 to demonstrate that the new design concepts would deliver dramatic performance improvements. The trial proved that the design concepts worked. The average service time was 2.3 days, compared with the traditional service time of five days. If necessary, the team was able to deliver same-day service. There was the perception that fewer errors were made and that customer satisfaction was significantly improved. However, the lack of comparable prior error rates and Centrex-only customer satisfaction measures made it difficult to quantify the exact improvements in these latter areas. Also the lack of fully operational information technology applications meant that some tasks had to be carried out manually. This made it difficult to estimate how well the design would deliver the stretch objectives. The absence of the desired IT capabilities was counterbalanced by the competencies and motivation of the trial team: four high performers who had volunteered for the project and who were highly committed to its success.

By the end of 1993, five of the seven regions had implemented pilots, but none had accomplished the goals that were initially established. The regions 
TABLE 5

\begin{tabular}{|c|c|c|c|c|c|c|c|}
\hline Benefits Realized & $\begin{array}{c}\text { Region } \\
\text { A }\end{array}$ & $\begin{array}{c}\text { Region } \\
\text { B }\end{array}$ & $\begin{array}{c}\text { Region } \\
\text { C }\end{array}$ & $\begin{array}{c}\text { Region } \\
\text { D }\end{array}$ & $\begin{array}{c}\text { Region } \\
\text { E }\end{array}$ & $\begin{array}{c}\text { Region } \\
\text { F }\end{array}$ & $\begin{array}{c}\text { Region } \\
\text { G }\end{array}$ \\
\hline Start of pilot & - & - & $\begin{array}{l}\text { QTR I, } \\
93\end{array}$ & $\begin{array}{l}\text { QTR 3, } \\
92\end{array}$ & $\begin{array}{l}\text { QTR 4, } \\
92\end{array}$ & $\begin{array}{l}\text { QTR 2. } \\
93\end{array}$ & $\begin{array}{l}\text { QTR I. } \\
93\end{array}$ \\
\hline $\begin{array}{l}\% \text { of orders processed when } \\
\text { the customer want it }\end{array}$ & & & $100 \%$ & $99 \%$ & $100 \%$ & $99 \%$ & $100 \%$ \\
\hline$\%$ of cost reduction (per order) & & & $49 \%$ & $50 \%$ & $50 \%$ & * & $36 \%$ \\
\hline$\%$ of reduction in errors & & & * & $50 \%$ & * & ${ }^{*}$ & $20 \%$ \\
\hline$\%$ of customers satisfied & & & $97 \%$ & $95 \%$ & $97 \%$ & $>90 \%$ & * \\
\hline
\end{tabular}

- No comparable baseline data was available to quantify exact improvement.

realized cost reductions of $35-50 \%$, a $20-50 \%$ reduction in errors, and customer satisfaction ratings of $90-97 \%$ (Table 5). However, none had accomplished the goals that were initially established. The gaps were due to a number of reasons. First, only three of the five pilot regions implemented the new roles prescribed by the design. In two regions, labor union issues made it unfeasible to implement the new roles in 1993. Secondly, none of the pilot regions felt the need to implement the pre-defined inventory feature proposed in the initial design and implemented during the trial. Finally, not all of the information technologybased capabilities assumed with the new design were available to the regions at the end of 1993.

Not only did the initial field implementation only partially meet the objectives, the project also deviated in terms of the original time schedule. When the Centrex redesign team started, management assumed full implementation of the new design by 1993. The initial sponsor of the project noted, "I envisioned it would take us 6-9 months to complete the redesign and establish pilots in all of the regions." At the end of 1993, five regions had pilots underway and the other two regions were planning to start pilots in 1994 (Table 6). Several major barriers were not considered by the project team at the outset of the project: labor issues, the time it would take for the regions to understand and accept the new design, the time it would take to select and train employees for the new roles, and the lead time for the new information technology-based applications.

The roll-out plan for each region was delayed because management and local union leadership had to understand and agree to the proposed positions before they could be institutionalized, given that $70 \%$ of Pacific Bell's employees were unionized. Also, each region that piloted the new design first conducted its own analysis of the current state of its order fulfillment process. This analysis took from 2 to 4 months. Each region then went through an abbreviated design process where it chose those components of the corporate Centrex design which addressed its needs. Because of the lead time for corporate IT applications, some 


\section{TABLE 6}

\begin{tabular}{|c|c|}
\hline Date & Event/Description \\
\hline $4 / 91$ & $\begin{array}{l}\text { Kickoff of Design Team } \\
\text { A design team was formed and chartered to deliver a new design within } 60 \text { days }\end{array}$ \\
\hline $6 / 91$ & Initial Design Completed \\
\hline $8 / 91$ & $\begin{array}{l}\text { Subteams formed for trial development } \\
\text { Four sub-teams were formed to plan various aspects of the trial. The teams focused on the } \\
\text { following aspects of the design: Job description, predefined packages, modeling and metrics, } \\
\text { information technology. }\end{array}$ \\
\hline $10 / 91$ & Start of technology development for trial \\
\hline$|1 / 9|$ & $\begin{array}{l}\text { Employees selected for the trial } \\
\text { Four high-performing employees were selected from a pool of volunteers. }\end{array}$ \\
\hline $1 / 92$ & $\begin{array}{l}\text { Trial started } \\
\text { The } 60 \text {-day trial was started in Region A. }\end{array}$ \\
\hline $5 / 92$ & Trial disassembled \\
\hline Summer 92 & Analysis of trial data, presentation of results to regions \\
\hline $7 / 92$ & Region D started pilot \\
\hline $11 / 92$ & Region E started pilot \\
\hline IQtr/93 & Regions $C$ and $G$ started pilots \\
\hline 2Qtr/93 & Region F started pilot \\
\hline 1994 & Regions $\mathrm{A}$ and $\mathrm{B}$ planned pilots \\
\hline
\end{tabular}

regions designed their own. ${ }^{16}$ Consequently, the Centrex reengineering project did not meet the initial performance targets. Also, thirty to thirty-six months turned out be a more reasonable time frame for the roll-out than the 18 months planned initially.

Pacific Bell's experience provides insight regarding the radical change assumption of reengineering. The Centrex design team sought to accomplish radical change outcomes, and the stretch objectives established at the outset of the design process encouraged the design team to fundamentally change the way that the order fulfillment process was carried out. However, such dramatic changes could not be implemented in a short time frame. The broader cultural and political climate, and the lead time necessary for training and information technology-based applications, required a field-driven, evolutionary implementation approach. One cause of the modified timetable and performance outcomes was the difficulty the regions encountered when they attempted to implement the "clean slate" design.

\section{Reengineering Assumes a Clean Slate Change}

A clean slate design, is prevalent in the early writings on reengineering. Even in his original reengineering article, Michael Hammer proclaimed "Don't 
automate, obliterate," thereby suggesting that reengineering design groups should throw away all existing processes, activities, systems, and people. ${ }^{17}$ In so doing, the redesign group could then define processes based on the way that work should be done unconstrained by current organizational customs and values. Hammer and Champy noted, "Reengineering ignores what is and concentrates on what should be." ${ }^{18}$ They elaborated:

When someone asks us for a quick definition of business process reengineering, we say that it means 'starting over.' It doesn't mean tinkering with what already exists or making incremental changes that leave basic structures intact. It isn't about making patchwork fixes -jury-rigging existing systems so that they work better. It does mean abandoning long-established procedures and looking afresh at the work required to create a company's product or service and deliver value to the customer. ${ }^{19}$

Similarly, others advocate that only with "a clean-slate approach to process redesign ... can companies avoid the classic reengineering pitfalls." ${ }^{20}$

The initial reengineering design for Centrex met the clean slate requirement. ${ }^{21}$ To encourage "out of box thinking," several members of the cross functional 13-member design team had no direct knowledge of Centrex provisioning and challenged the status quo. The leadership of the design team was dedicated to the project full time to free themselves from the constraints and concerns of day-to-day operations. The team also conducted visits with and external benchmark studies of companies that exemplified highly innovative approaches to order fulfillment and were in industries unrelated to telecommunications. As a senior manager noted:

"During the design, the team went well beyond thinking of the best way to fulfill a Centrex order. They sought out the best in class for order fulfillment, in general. The team visited an insurance company that is a recognized leader in the processing of commercial claims. The team members analyzed that firm's process to understand how we could radically change the Centrex provisioning process."

Early in trial it became necessary to revise the design to take into account the existing organization structure, information technology-based capabilities, as well as the concerns of the local site management and unions over the new roles prescribed by the design. Also, because of lack of IT support, the scope of the trial was scaled back to include only simple Centrex orders. The unavailability of sophisticated communications technology required the members of the "virtual team" to be co-located in the same physical space. The co-location allowed the team to tightly coordinate activities and perform a series of activities in parallel rather than in sequence. Another barrier for virtual collocation was the difficulty of the concept. The sponsor of the project noted, "Individuals had real difficulty grasping the notion of parallel execution of interrelated order activities by team members who could not see each other."

During the pilots, labor union issues were challenging in two of the regions. In those regions, management anticipated that significant union 
negotiations would be required to redefine roles and jobs responsibilities, thereby delaying the realizations of benefits. The managers of those regions decided to work within the confines of the current state. Rather than redefine roles, they collocated those employees who were involved in Centrex provisioning. The collocation led to improvements in time to complete the order, in error rates, and in customer satisfaction. Some additional unplanned costs were incurred because of office space and layout requirements.

The clean slate design was also constrained by the existing legacy systems (old, typically mainframe-based systems) and the lead time to develop the new advanced information technology applications that would interface with the legacy systems. In 1992, a new group was formed to build the highly complex front-end systems and networks and to interface them with the legacy systems. Nevertheless, the development work was still underway at the end of 1993 on the order inquiry, inventory, and scheduling applications.

Pacific Bell's experience highlights the fact that one can design assuming a clean slate, but one must implement assuming an existing state. During the design phase, a clean slate can foster "out of box thinking." However, the existing organizations had structures, job definitions, and legacy systems that necessitated compromises during implementation. The inability to achieve the stretch objectives in the time frame envisioned and without the constraints of the past led to an implementation that also violated the third assumption of reengineering.

\section{Reengineering Focuses on End-To-End Process Redesign}

The third assumption is that reengineering focuses on end-to-end process redesign where a process is defined as "a set of activities that, taken together, produce a result of value to a customer." ${ }^{22}$ A process focus emphasizes how work is done within the firm rather than the traditional product focus on what. ${ }^{23}$ Common end-to-end business processes in organizations include service delivery, product development, order fulfillment, and new market development. Reengineering typically concentrates on so called core processes that increase the organization's competitiveness. ${ }^{24}$

Process reengineering by definition implies that processes are repeatable and have enough elements of consistency (e.g., clearly identified inputs and outputs) to justify developing a common process for an organization. ${ }^{25}$ Customers, either within the firm or outside, are usually central to any redesign activity. A reengineering activity typically starts by understanding the existing process from the customer's perspective as well as by identifying customers' needs.

The redesign of Centrex provisioning was an end-to-end process, the order fulfillment process. The process started with the customer's order and was completed when the requested service was activated. Customer input was 
solicited to develop and validate the design. Further, the new design was highly integrated-assuming new tasks, organizational roles, and information systems.

During the trial, some aspects of the future state could not be implemented so the integrated design was compromised. For example, the provisioning team had to be collocated because IT support of the planned virtual team was not available. Also, management in several areas were unwilling to redefine job responsibilities as assumed in the design, therefore roles had to be redefined.

During the regional pilots, rather than implementing a new end-to-end process, the regions sought the "low hanging fruit." Since each region provisioned Centrex and since there was not a standard process across the regions, each had a different current state. Upon committing to pilot the new design, each region established its own goals for the new process. For example, two regions set out to reduce cost by $50 \%$, whereas one region aimed at a $40 \%$ reduction. Each region also carried out an analysis of the current state. The various regions then implemented the parts of the new process that corresponded to the immediate problems and opportunities faced by that locale. Yet, by attacking the "low hanging fruit," the regions significantly improved the Centrex provisioning process (e.g. 36-50\% cost reductions)..

The customization of the design by the regions can perhaps best be explained by differing motivations for change. For example, the region where the trial was carried out found it was very advantageous to predefine packages (i.e., pre-program the central office switch with those features most frequently ordered) because of the workload balancing flexibility that resulted. That region also concluded that if it maintained an inventory of pre-defined packages, it did not need to collocate people. When a "non-standard" order was received, the lines of communication had been established for physically separated functions and or departments to coordinate with one another. The trial region was also different than the other regions in that it included several metropolitan areas, which had a large concentration of potential Centrex customers.

As described earlier, the relationship that the union and management had in a particular region was a strong factor in determining whether the new roles were implemented during the pilot phase. For example, the two regions that did not change roles for the pilot planned to adopt the new roles once the national union and corporate staff management sorted out appropriate compensation and responsibilities for those new roles. In other regions, close union-management relationships allowed the regions to "trial" the new roles during the pilot in advance of the renegotiated union contract.

Each of the 5 pilot regions modified the design in light of some unique characteristic of the region or some management constraint. The modified designs also helped regions to manage the level of risk associated with the project and to make the changes more palatable to their respective constituents. Perhaps there would have been less variability among what was implemented 
in the various regions if corporate management had mandated that the regions adopt the redesign as implied by the fourth reengineering assumption.

\section{Reengineering Must Be Top-Down Directed}

The fourth assumption of reengineering is that it must be top-down directed. Hammer and Champy advocate reengineering as a form of work design that must be top-down. ${ }^{26}$ Because the processes being addressed usually span across different functional areas, only the highest levels of management are argued to have the broad perspective to identify the core processes and to possess the political power to force collaboration and mandate the breadth of changes. According to Davenport, "Because large firms' structures do not reflect their cross-functional processes, only those in positions overlooking multiple functions may be able to see opportunities for innovation." ${ }^{27}$ Consequently, a high-level design-including the overall flow of the process and its sub-processes, performance objectives, and inputs/outputs-must be done by a cross-functional design team whose responsibility is to study the process in its entirety and consider relevant enablers and benchmarks in its design. The champions and sponsors of this team have to "own," or be responsible, for all the pieces and interfaces of the process.

Hammer and Champy stress that reengineering cannot happen from the bottom-up for two reasons. First, employees and middle managers do not have the broad perspective required by reengineering. Second, middle managers do not have the authority to enable the cross-functional process transformation that is associated with reengineering. ${ }^{28}$ Others who have studied radical organizational design, maintain that for fundamental changes to occur in an organization, personal involvement from the executive leadership is required in developing the case for action, in design, and in the development of implementation plans. ${ }^{29}$ Executive management must also have a hands-on role in the implementation itself, "motivating constructive behavior, shaping political dynamics, managing control during the transition period, and managing external constituents." ${ }^{30}$ It has been reported that, in the most successful reengineering projects, top executives spent between $20 \%$ and $60 \%$ of their own time on the project. ${ }^{31}$ More importantly, the time commitment of the senior executives was considerably higher in implementation than in design.

In the Centrex project, top-down goals and objectives were formulated at the top of the organization. Senior executives were also visibly involved in the initial phases of the project. The project was initiated by a corporate executive vice president who forged a partnership with a regional general manager. The project was supported and approved by the Pacific Bell senior management team. Their approval signaled the wide recognition that the firm's flagship product was increasingly being replaced by less expensive substitute products, which also hindered sales of other products and services. The sale of Centrex opened up sales opportunities for many other products. 
Whereas top-down goals and objectives created the motivation for reengineering, bottom-up acceptance of the design drove implementation success. The visible involvement of the senior executives decreased as the project progressed. Marketing of the new process to the regions was accomplished by the project team composed of middle managers and staff.

The initial sponsor of the project commented, "When the regional units started to take ownership and responsibility for the success of the project, my role diminished to one of ensuring adequate financial resources." At Pacific Bell, no corporate mandate was issued to implement the design and do so by a certain date. The team leader of Centrex reengineering explained:

"We [corporate] have provided the vision for the new process and have proven the concepts and the benefits. Process implementation must be a decision of a particular business. The regions that have piloted the new process have shown the benefits on the production scale. The pilots have created a tremendous grass-roots interest in getting Centrex reengineering implemented. People now come to us who want to do. We [the Centrex project team] no longer have to sell this to the regions."

The actual implementation of Centrex reengineering was a business unit, not a corporate, initiative. Each pilot implementation required that the business unit general manager establish Centrex reengineering as a priority. This meant appointing a project manager who became the champion of the new process. This also meant that the general manager personally stayed involved in order to remove organizational barriers that might hinder the reengineered process. The degree to which the general manager was personally involved translated into what was achieved. The one region with the most accomplishments had the most visibly involved general manager.

Yet, none of the regional general managers mandated Centrex reengineering. In the most extreme case, one regional business unit general manager made a public commitment to implement the new roles and the new process across all Centrex orders. In other regions, a much more gradual roll-out occurred. This has generated some frustration. One manager in a region complained, "We know the new process works. Management and labor should mandate this process."

The void of a corporate or regional mandate resulted in each region developing its own "case for action" before proceeding with implementation. Some regions were motivated by the opportunity to fix a perceived broken process. These regions had already documented or unveiled customer or field employee problems with Centrex provisioning. Others saw the opportunity to improve the competitive positioning of their organization. The rest opted to change those pieces of the new process that would face the least resistance. The former two groups were likely to embrace aggressive objectives as well as a larger part of the new process. The last group had less ambitious, more 
incremental process improvement goals and tended to implement only a piece or two of the new process. A manager remarked:

"Everyone agrees that the concepts of the design are the right ones. Disagreement seems to exist across the regions on to what extent and how to implement the design. Further, some regions will be happy if they can realize a $10 \%$ reduction in cost or error rates."

\section{Reengineering Is Information Technology Enabled}

Our discussion of the first four assumptions shows that information technology is one reason that the realized outcomes did not meet the initial assumptions of reengineering. The fifth assumption of reengineering is that information technology (IT) plays a prominent role in the design process itself, as well as in the final redesigned business process. This is different from the conventional wisdom that assumes a process should be designed before investigating enabling technology or systems. For example, the author of Process innovation noted, "To suggest that process designs be developed independently of IT or other enablers is to ignore valuable tools for shaping processes." ${ }^{32}$ Another recommends that "current and emerging IT and IS capabilities...should be used as a lever for designing new organizations and associated business processes. ${ }^{233}$ Hammer and Champy similarly describe the requirement to include IT during the design of a new process as the challenge to think inductively. They noted, "Reengineering, unlike automation, is about innovation. It is about exploiting the latest capabilities of technology to achieve entirely new goals. One of the hardest parts of reengineering lies in recognizing the new, unfamiliar capabilities of technology instead of its familiar ones." ${ }^{134}$ They believe that technology can play a role in helping members to think of new ways of working that had not been envisioned before.

Besides helping to create new alternatives to accomplishing work, IT is seen as an integral part of the final implemented process. ${ }^{35}$ Among the capabilities that IT offers are instantaneous worldwide reach, shared database access, ability to capture and repeat the decision processes of experts, a prodigious memory, and the ability to personalize almost any transaction based on the needs of the user, organization, or customer.

During the design phase of Centrex, knowledge of advanced IT capabilities enabled the development of a radical design; however, implementation proceeded without much of the advanced IT capability. During the design phase of Centrex reengineering, the capabilities of advanced IT-based systems, such as groupware and single system image, were assumed to be available. These systems were deemed necessary to provide seamless access to legacy systems and to enable real-time information sharing across virtual team members. The assumed capabilities of advanced IT-based systems influenced the design. 
Prototype applications were developed for use during the trial. They changed the way that the employees interacted with technology. A manager noted, "Before the trial, the employees saw the systems as performing the business process; their job was to make the systems work. After the trial, they saw the team performing the business process and the systems serving as an information tool." The technology was enabling rather than mechanizing the business process.

Yet the trial and pilots highlighted that the role of IT is secondary to the establishment of collocated teams. A regional business unit manager noted, "During the trial, there was a lot of energy around teams." Another regional business unit manager estimated that $80 \%$ of the productivity improvement realized in his region resulted from the formation and the use of collocated teams. The rest of the productivity improvement was due to the new technology support.

Since the lead-time to develop the advanced-IT applications and to interface them to the 10-12 legacy systems were long and/or costly, human systems and structures were developed for the trial that were not dependent on the most advanced IT capabilities assumed by the original design. For example, trial members were given access to additional systems from their workstation, but the data from those systems was not integrated. Completing the trial before developing full-blown systems permitted the validation of the design before a significant IT development effort was undertaken. Further, Pacific Bell was able to gather systems requirements in light of experiences with the new work roles and procedures.

The Centrex reengineering initiative suggests that the capabilities of advanced-IT can help envision radical process designs and enable small trials of the process. ${ }^{36}$ Yet managers must be careful that systems do not inhibit the implementation of new processes. Whereas Pacific Bell was able to deploy Centrex and reap significant benefits with little advanced IT support, we have observed many cases where the unavailability of some IT-based capability became the excuse for not implementing the new proven process. However, someone at Pacific Bell (for example, a process owner at the corporate level) must be a keeper of the original vision and continue to push for technology that enables the full vision.

\section{Summary and Conclusion}

Reengineering can be a powerful change phenomenon. However, managers who consider undertaking reengineering need to understand how it unfolds in practice. Just as we have found with other management innovations such as total quality management, ${ }^{37}$ putting the innovation to work rarely matches the initial concepts and models of the innovation. The Pacific Bell Centrex Reengineering initiative, an acknowledged reengineering success story, 
highlights some of the limitations of the broadly professed assumptions of reengineering. Our analysis suggests the following revised assumptions:

- Reengineering design may be radical, but implementation is incremental.

- Reengineering design assumes clean slate change. However, implementation will be limited by those constraints that management cannot or will not remove.

- Reengineering design focuses on end-to-end process redesign. Reengineering implementation often focuses on the perceived most-broken pieces.

- Reengineering design is top-down directed, but implementation requires acceptance from the bottom-up.

- Reengineering design is enabled by information technology, but the implementation might be initiated without much of the assumed IT capability.

The first assumption declared that reengineering results in a radical change. Our analysis of Pacific Bell's experience with Centrex suggested that the reengineering initiative resulted in a radical new design for Centrex provisioning. However, what was implemented in the regions differed from the design and was not as radical as planned. BPR efforts need a balance between stretch and realistic time frames and objectives in order to manage expectations for the continued support of the project.

The second assumption specified that reengineering assumes clean slate change. The redesign of the Centrex provisioning process was carried out assuming a clean slate. However, the trial and regional pilots, had to be implemented in "non clean slate" settings and were therefore limited by the internal and external organizational constraints and roadblocks that regional and corporate management did not remove. Again, expectations have to be managed throughout the organization regarding the areas that can be challenged and changed as well as the lead time required for making changes in these areas.

The third assumption highlighted the end-to-end process focus that is typically associated with reengineering. At Pacific Bell, the design that was developed by the corporate reengineering group was very integrated and assumed the various aspects of the end-to-end provisioning process. During the regional pilots, however, managers implemented those aspects of the design that would bring them the most benefit for the least effort. Hence, for local implementation, a close linkage has to exist between the imminent problems faced and the solutions proposed in BPR.

The fourth assumption suggests that reengineering must be top-down directed. At Pacific Bell, some regional management did encourage Centrex reengineering. However, implementation was enabled where front-line employees embraced the initiative. In BPR efforts, ownership and commitment is needed throughout the organization, particularly during implementation. 
The final assumptions stated that reengineering is enabled by IT. At Pacific Bell, a large portion of the benefits of reengineering accrued because of the structural and role changes that were made. The new work processes were implemented first; information technology capabilities were rolled out gradually.

\section{Implications of the Revised Assumptions}

As the first two assumptions state, radical implementation is difficult to accomplish in an existing organizational context. Management of expectations is key. Although stretch objectives and aggressive time frames are needed to get the change program underway, the organization and management must be ready to accept a slower pace and more moderate success in implementation. However, if a radical implementation is required, managers must seek ways to create new organizations. The establishment of a greenfield site or a move to a new location might provide the opportunity for such a new organizational context.

In keeping with the spirit of the first implication, the Pacific Bell case suggests that it may be unrealistic to assume that one can implement an endto-end redesign in an existing organization. Where it is not possible to establish a new organization, it is important to go after the low hanging fruit and change incrementally month after month or year after year, while keeping an eye on the ultimate goal of end-to-end process innovation.

The third implication of our findings at Pacific Bell is the importance of bottom-up buy in of a design. The fact that the Pacific Bell regions engaged in a redesign activity fostered ownership of the design. It may be important to allow those affected by changes to customize pieces of a design in a reengineering project.

Another implication is that managers must plan for the lead time associated with IT application development. Further, one should not allow the project to become side-tracked because of the unavailability of the IT applications assumed in the design. It may be possible to make significant strides toward the accomplishment of the goals of redesign without the assumed IT applications.

In conclusion, we acknowledge that the restated reengineering assumptions are by no means the last word on reengineering. The Centrex case and our other research sites reflect an early stage of reengineering. Reengineering is still in its infancy as organizations are just beginning to institutionalize processes that have resulted from their early reengineering initiatives. Reengineering zealots might argue that Pacific Bell had a flawed process; top management should have required that all of the regions adopt the Centrex design without deviation. However, given the cultural and political climate at Pacific Bell, which encouraged entrepreneurship within the regions, senior management could not mandate the implementation of the Centrex design. 


\section{APPENDIX Study Methodology}

The current case study, the Centrex reengineering project, is a product of an ongoing research study on managing change in business process reengineering. The multi-year research study has multiple phases. The first phase involved a retrospective analysis of three reengineering projects in three companies. Change management tactics used in the projects were identified and categorized to help build a theoretical "lens" for the research. ${ }^{38}$

The second phase involved a field survey with 35 companies on their reengineering projects. The companies studied were selected because they claimed to have one or more reengineering projects that were underway or had recently been completed. A definition of a reengineering project was one of the main outcomes of this phase. A reengineering project was defined in terms of the initial objectives of the project. It is an effort that the management in the company launches as a radical organizational initiative. A project aims to accomplish change with the following characteristics:

- a cross-functional scope (more than two functional areas)

- a business process focus (versus, for example, a technology, information, or organizational structure focus)

- a simultaneous change in: organization design (e.g., teams, delayering, consolidation of functions); culture; and information technology

- radical performance improvements (over 50\% improvement in cost, quality, cycle-time, customer satisfaction, and/or market share).

Change that shares the above characteristics goes counter to conventional ways an organization has accomplished work. The definition was used to screen and select reengineering projects for in depth case studies of which Pacific Bell Centrex Reengineering is one example.

The Pacific Bell project is the first completed case study out of the longitudinal study phase. The phase involves longitudinal studies of 12 business reengineering projects in 8 organizations, five of which are service organizations and three of which are manufacturing organizations. Participants in the longitudinal case studies receive site visits every three to five months in addition to 30-60 minute phone conferences with the project manager or project leader on a regular basis. Site visit interviews involve organizational members such as the senior management of the firm, executive project sponsor, senior operating management of the project, reengineering project participants, and customer representatives of the process.

The Centrex reengineering project at Pacific Bell is an exemplar of a reengineering project in our longitudinal case study phase, both in terms of research process as well as the main project findings. Over 25 people at Pacific Bell were interviewed. Interviews were conducted with representatives of the senior leadership and all functional management affected or involved with the Centrex reengineering. Interviews were also conducted with representatives of all the geographical regions. (As of January 1994, the seven regions were 
collapsed to four regions). The interviews were semi-structured, with each interview lasting from forty-five minutes to one and a half hours. The two researchers attended all interviews, helping to increase the reliability and confidence of the perceptions and observations.

The findings of the Pacific Bell Centrex project as discussed in this article are being reinforced in the other 11 longitudinal case studies that are still in progress. Hence, this article reports the Pacific Bell project in the light of the observations from the other studies. Because of the representative nature of the project, the Pacific Bell Centrex reengineering initiative allows us to begin to refine the concepts and theory of reengineering.

\section{Notes}

1. M. Hammer and J. Champy, Reengineering the Corporation (New York, NY: Harper Collins Books, 1993). Also see T. Davenport, Process Innovation (Boston, MA: Harvard Business School Press, 1993).

2. M. Hammer, "Reengineering Work: Don't Automate, Obliterate," Harvard Business Review (July/August 1990), pp. 104-112.

3. Hammer and Champy, op. cit.

4. As a regional Bell operating company, Pacific Bell provides a variety of services, including dial tone and usage services, exchange access and billing services to inter-exchange carriers and information service providers, operator services, installation and maintenance of customer premises wiring, public communication services, and directory publishing. Approximately $70 \%$ of Pacific Bell's 50,000 employees are represented by unions. In 1992, the firm's total operating revenues were $\$ 8.7$ billion.

5. Davenport, op. cit., pp. 10-14.

6. Ibid., p. 14.

7. The BPR project definition was subsequently validated in 10 focus group meetings involving representatives from the 35 companies.

8. CSC Index served as consultants. In the late 1990s, CSC Index was considered a pioneer in reengineering methodologies and tools.

9. The assumptions are largely based on the books by Hammer and Champy, op. cit., and Davenport, op. cit.

10. Hammer and Champy, op. cit.

11. Hammer and Champy [ibid., p. 80] state that reengineering involves changing practically everything about the company-business processes, jobs and structures, management and measurement systems, values and beliefs, and the business system diamond.

12. Ibid., p. 5.

13. Ibid., p. 212.

14. For example, see M. Tushman, W. Newman, and E. Romanelli, "Convergence and Upheaval: Managing the Unsteady Pace of Organizational Evolution," California Management Review, 29/1 (Fall 1986): 29-44.

15. The case manager represents an unconventional way to accomplish administrative work. See T. Davenport and N. Nohria, "Case Management and the Integration of Labor," Sloan Management Review, 35/2 (Winter 1994): 11-24.

16. Most of the regionally developed IT applications were shared across regions.

17. Hammer, op. cit.

18. Hammer and Champy, op. cit., p. 53.

19. Ibid., p. 31. 
20. G. Hall, J. Rosenthal, and J. Wade, "How to Make Reengineering Really Work," Harvard Business Review (November/December 1993), pp. 119-131.

21. The team did not question the product or market strategy of Centrex.

22. Hammer and Champy, op. cit., p. 35.

23. For example, see Davenport, op. cit.

24. H. Johansson, P. McHugh, A. Pendlebury, and W. Wheeler, Business Process Reengineering: Breakpoint Strategies for Market Dominance (New York, NY: John Wiley and Sons, 1993).

25. Davenport, op. cit.

26. Hammer and Champy, op. cit.

27. Davenport, op. cit., p. 12.

28. Hammer and Champy, op. cit.

29. Tushman et al., op. cit.

30. Ibid., p. 41.

31. Hall et al., op. cit.

32. Davenport, op. cit.

33. N. Venkatraman, "IT-Enabled Business Transformation from Automation to Business Scope Redefinition," Sloan Management Review (Winter 1994), p. 78.

34. Hammer and Champy, op. cit.

35. Ibid.

36. Ibid.; Venkatraman, op. cit.

37. For example, see R. Krishnan, A. Shani, R. Grant, and R. Baer, "In Search of Quality Improvement: Problems of Design and Implementation," Academy of Management Executive, 7/4 (1993): pp. 7-20; R. Grant, R. Shani, and R. Krishnan, "TQM's Challenge to Management Theory and Practice," Sloan Management Review, 35/2 (Winter 1994): pp. 25-36.

38. D. Stoddard and S. L. Jarvenpaa, "Business Process Redesign: Tactics for Managing Radical Change," JMIS (Summer 1995). 
Copyright of California Management Review is the property of California Management Review and its content may not be copied or emailed to multiple sites or posted to a listserv without the copyright holder's express written permission. However, users may print, download, or email articles for individual use. 